\title{
Award Papers from Turkish Society of Orthopaedics and Traumatology 2013
}

\section{Editorial Comment: Award Papers from Turkish Society of Orthopaedics and Traumatology 2013}

\section{Feza Korkusuz MD}

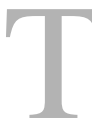

he Turkish Society of Orthopaedics and Traumatology (TOTBID) was established in 1970, and currently consists of 1940 active members. More than 1280 orthopaedic surgeons from 13 countries attended the $23^{\text {rd }}$ Annual National Turkish Orthopedics and Traumatology Congress from October 29 to November 3, 2013 in Antalya, Turkey.

\footnotetext{
The author certifies that he, or any member of his immediate family, has no funding or commercial associations (eg, consultancies, stock ownership, equity interest, patent/ licensing arrangements, etc) that might pose a conflict of interest in connection with the submitted article.

All ICMJE Conflict of Interest Forms for authors and Clinical Orthopaedics and Related Research ${ }^{\circledR}$ editors and board members are on file with the publication and can be viewed on request.

The opinions expressed are those of the writers, and do not reflect the opinion or policy of $\operatorname{CORR}^{\circledR}$ or the Association of Bone and Joint Surgeons ${ }^{\circledR}$.
}

F. Korkusuz MD ( $\square)$

Hacettepe University Medical Faculty, Department of Sports Medicine, Sihhiye, 06100 Ankara, Turkey

e-mail: feza.korkusuz@hacettepe.edu.tr; feza.korkusuz@gmail.com
This symposium, while small, represents some of the best papers from the Congress; all of the manuscripts published in this symposium won awards at the congress. These manuscripts present new findings on the following topics: (1) early onset scoliosis, (2) latissimus dorsi tendon transfer, and (3) tibial nonunions. The modified growing rod technique with apical and intermediate anchors provided satisfactory curve control in early-onset scoliosis patients. Tenodesis after latissimus dorsi tendon transfer caused loss of strength with time and progressed arthroplasty. Tibial nonunion with bone loss was treated with a circular external fixator and an intramedullary rod in five patients.

We are excited by the research we present on these important clinical topics, because it is directly applicable to patient care. Spine surgeons may now consider leaving a mobile segment to better correct curves in earlyonset scoliosis cases with the growing rod technique. Surgeons who routinely transfer the latissimus dorsi tendon during shoulder surgery should be

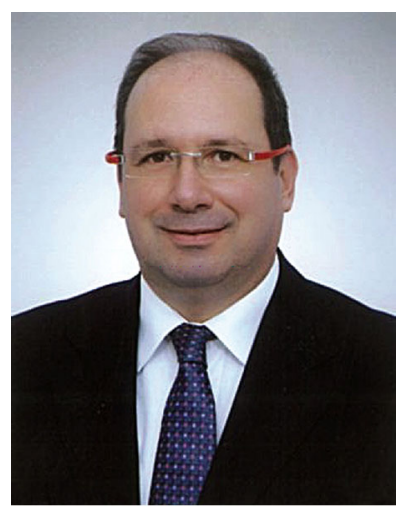

Feza Korkusuz MD

aware that tenodesis may cause strength loss and progresses arthritis. Surgical treatment of tibial nonunions is a challenging issue and the combination of a circular external fixator with an intramedullary rod may help to solve the problem.

TOTBID is proud of its affiliation with Clinical Orthopaedics and Related Research ${ }^{\mathbb{R}}$, pleased to present this first symposium consisting of a selection of our award-winning papers, and enthusiastic about even larger collaborations with $C O R R^{\circledR}$ in the future. 